\title{
Spirituality, religion and health: evidence and research directions
}

\author{
David R Williams and Michelle J Sternthal
}

A 2001 publication identified over 1200 studies that had examined the relationship between some aspect of religious belief or behaviour and some indicator of health. ${ }^{1}$ It concluded that most studies had found a positive association between religion and physical and mental health. There is ongoing scientific interest in this topic and some debate about the relevance of these findings to Australia. ${ }^{2,3}$ We provide a brief overview of the empirical evidence linking measures of spirituality or religious involvement to health, with an emphasis on recent studies and studies from Australian research. We outline some of the challenges in this area and priorities for future research.

"Spirituality" appears to mean different things to different people, and we do not attempt here to specifically define the term or to distinguish it clearly from "religion". For many, spirituality refers to an individual's attempt to find meaning in life, which can include a sense of involvement with the transcendent outside institutional boundaries. ${ }^{4}$ Religion tends to refer to aspects of belief and behaviour, including spirituality, that are related to the sacred or supernatural and are grounded in a religious community or tradition. Most of the research in this area to date has been based on measures of religiosity rather than spirituality.

\section{Levels of spirituality}

Levels of religious belief and behaviour are remarkably high in the United States, and most Americans believe that their spiritual beliefs and behaviours influence their health. Over 90\% of American adults say that they pray and believe in God or a higher being, two-thirds are members of churches or synagogues, $40 \%$ attend religious services regularly, and a majority of patients would like medical providers to discuss the spiritual aspects of their illness. ${ }^{5}$ Moreover, $79 \%$ of US adults believe that spiritual faith can help people recover from illness, injury, or disease. ${ }^{6}$

Levels of religious involvement are lower in Australia, but still relatively high. ${ }^{3}$ Census figures show that the proportion of the Australian population claiming some kind of religious affiliation declined from $97.5 \%$ in 1901 to $88.9 \%$ in $1966,77.8 \%$ in 1981 and $73.9 \%$ in $2001 .^{7}$ However, religious affiliation varies by demographic characteristics, with levels being especially high among elderly people and people living in non-metropolitan areas. ${ }^{8}$ Time-use data for Australia have shown that $14 \%$ of households engage in some form of religious activity weekly, 10\% engage in religious activities daily, and $74 \%$ believe in God or a higher life force or spirit. ${ }^{9}$

Levels of spirituality are also fairly high in Australia, with a third of adults indicating that the desire for spiritual life is very important or the most important principle guiding their lives, and an additional third saying it is important. ${ }^{10}$ Women value spirituality more than men, and formal education is positively related to valuing spirituality. At the same time, there appears to be a separation between spirituality and religiousness. Only 30\% of those who value spirituality attend religious services monthly or more. A similar pattern appears to be evident in the US, where, although levels of religious attendance have experienced some decline in recent decades, some dimensions of spirituality or religiousness outside institutional contexts appear to be on the increase. ${ }^{5}$

\section{ABSTRACT}

- Levels of spirituality and religious beliefs and behaviour are relatively high in Australia, although lower than those in the United States.

- There is mounting scientific evidence of a positive association between religious involvement and multiple indicators of health.

- The strongest evidence exists for the association between religious attendance and mortality, with higher levels of attendance predictive of a strong, consistent and often graded reduction in mortality risk.

- Negative effects of religion on health have also been documented for some aspects of religious beliefs and behaviour and under certain conditions.

- Health practices and social ties are important pathways by which religion can affect health. Other potential pathways include the provision of systems of meaning and feelings of strength to cope with stress and adversity.

MJA 2007; 186: S47-S50

\section{Religion and health}

Recent reviews continue to provide further evidence of an association between religious involvement and health. Religion-associated variables have been shown to have protective effects for multiple mental health outcomes, including wellbeing, suicidal behaviour and substance misuse. ${ }^{11}$ A critical review of 17 studies found that religious attendance and intrinsic (internalised) religion tend to be associated with reduced anxiety, while extrinsic (utilitarian) religion tends to be positively associated with anxiety. ${ }^{12}$ A metaanalysis of 147 studies concluded that there was a robust but modest inverse association between religiousness and depressive symptoms. ${ }^{13}$ However, other data reveal that the evidence for associations between religiosity and schizophrenia is mixed. ${ }^{14}$ Australian studies have also noted that religion may have a potential therapeutic role in the treatment of depression. ${ }^{15,16} \mathrm{~A}$ series of randomised controlled trials found that spiritually augmented therapies were more successful than non-spiritual conventional therapies in reducing patients' depressive symptoms, improving treatment and adherence, and minimising the risk of relapse. ${ }^{4,17}$ Studies of adolescent behaviour have found that higher levels of religious involvement are inversely related to alcohol and drug use, smoking, sexual activity, depressive symptoms and suicide risk. ${ }^{18,19}$ Studies of Australian school students have also shown that religiosity is inversely related to a broad range of risk behaviours. ${ }^{20,21}$

A meta-analysis of 49 studies of religious coping found that positive forms of religious coping were related to lower levels of depression, anxiety, and distress, while negative forms of religious coping were associated with poorer psychological adjustment. ${ }^{22}$ Similar findings come from reviews of studies of religious beliefs and coping among HIV-positive individuals. ${ }^{23}$ These studies have also found that spirituality and religion are positively related to 


\section{SPIRITUALITY AND HEALTH}

immune system function. Although Koenig et $\mathrm{al}^{1}$ reported that the majority of the studies of heart disease, blood pressure and cancer risk found salutary effects among the more religious, recent reviews of the evidence for an association between religion and cancer or cardiovascular disease are more equivocal. ${ }^{24,25}$ Both positive and negative findings have come from studies of religious coping and illness adjustment among cancer patients. ${ }^{26}$

A systematic review of randomised controlled trials has found that religious prayer improved health outcomes in coronary patients and survival among children with leukaemia. ${ }^{27}$ Islamicbased psychotherapy also speeded recovery from anxiety and depression among Muslims. ${ }^{27}$ However, a recent well designed study of intercessory prayer found a small negative effect of prayer on patients in a coronary care unit. ${ }^{28} \mathrm{~A}$ recent review of 35 studies of the relationship between religiosity and health-related physiological processes found that both Judaeo-Christian and Eastern religious practices were associated with reduced blood pressure and improved immune function; moreover, Zen, yoga, and meditation practices correlated with lower levels of stress hormone and cholesterol and better overall health outcomes in clinical patient populations. ${ }^{29}$

Recent reviews on religion and health have all emphasised the many limitations of the existing research. These include the scarcity of multidimensional, psychometrically tested measures of religion; few measures of spirituality; the widespread use of crosssectional data; potential confounding by omitted sociodemographic, social, and health variables; and a paucity of longitudinal studies.

\section{Religious attendance and mortality}

A well documented association is the inverse relationship between religious attendance and mortality. For example, a US national study of 21000 adults documented a strong graded association between religious attendance and mortality, with people who had never attended services having a 19 times higher risk of death over an 8-year period than those who attended more than once a week. ${ }^{30}$ This association existed for most causes of death. Striking differences in life expectancy were also evident. Life expectancy at age 20 for people who attended services more than once a week was, on average, seven and a half years longer than those who never attended. This association was even stronger in African Americans, with a 13.7-year difference in life expectancy. ${ }^{30} \mathrm{~A}$ meta-analysis of 42 studies, surveying nearly 126000 people and controlling for sociodemographic and physical health status factors, concluded that active religious involvement increased the odds of being alive at follow-up by $26 \%$. These effects were stronger for women than men, possibly due to differences between men and women in the psychosocial support that they receive from religion. ${ }^{31}$ A rigorous review of the empirical evidence for the association between religion and health concluded that the scientific evidence is strongest for the religious attendance-mortality association. ${ }^{32}$ The report concluded that religious service attendance was associated with a "strong, consistent, prospective and often graded reduction in risk of mortality". After adjusting for confounding factors, the association between attendance and mortality was reduced by about $25 \%$. The evidence was strongest for cardiovascular disease.

\section{Negative effects of religion}

Attention has also been given to the potential for negative effects of religion on health. Historically, religion has sometimes been used to justify hatred, aggression, and prejudice. ${ }^{33}$ It can be judgemental, alienating and exclusive. Moreover, although religious participation may foster beneficial social networks, social relations may also be a source of stress. ${ }^{34}$ Failure to conform to community norms may evoke open criticism by other congregation members or clergy. Feelings of religious guilt and the failure to meet religious expectations or cope with religious fears can contribute to illness. ${ }^{35}$ Parents' reliance on faith healing instead of appropriate medical care has led to negative outcomes and death for many children. ${ }^{36}$

Certain types of religious coping may also adversely affect health. An extrinsic religious orientation and negative religious coping has been associated with elevated symptoms of depression, ${ }^{13}$ and negative interpersonal religious experiences and congregational criticism have been associated with increased risk of depression among adolescents. ${ }^{18}$ A longitudinal cohort study of medically ill patients found that religious doubts and struggle were associated with a higher risk of mortality. ${ }^{37}$ There is also interest in the potential contribution of religious participation to obesity, but the data are equivocal. Some studies have found that, independent of socioeconomic status and health behaviours, body mass index varied by religious denomination and that religious attendance was positively associated with weight. ${ }^{38}$ However, a recent US national study found that the association between religious attendance and overweight/obesity could be explained by sociodemographic and health variables. ${ }^{39}$

\section{Religion and health pathways}

Health behaviours encouraged or proscribed by particular religions are one explanatory mechanism for how religion can affect health. Early studies of Mormons and Seventh-day Adventists in the US ${ }^{1}$ and Australia ${ }^{40-42}$ documenting lower risk of cancer and other diseases in these groups than in the general population assumed a central role for health practices. Seventh-day Adventist teaching, for example, prohibits the use of tobacco and alcohol and encourages vegetarianism. Research on Seventh-day Adventists has documented the negative effects of meat and dairy consumption in the aetiology of cardiovascular disease and specific cancers, as well as the beneficial effects of consuming nuts and maintaining lean body weight. ${ }^{43,44}$ More generally, research in both adults and adolescents has suggested a strong association between religious involvement and a broad range of healthy behaviours, including behaviours for which there is no specific religious teaching. For example, a national study of high school seniors in the US found that religious students were more likely than their non-religious peers to wear seatbelts, eat breakfast, eat green vegetables and fruit, get regular exercise, and sleep at least 7 hours a night. ${ }^{45}$ Thus, religious participation could have a general moderating effect on lifestyle, or there may be selection bias, with people who are more religious differing in unmeasured ways from those less involved.

Social relationships are another potential explanatory factor. Social ties can provide both support and a sense of connectedness - but also, time demands, role conflicts and criticism. The Alameda County [California] Study found, for example, that religious attendance was linked to positive changes in both social ties and health behaviours over time. ${ }^{46}$ Researchers are also 


\section{SPIRITUALITY AND HEALTH}

exploring the extent to which religion and spirituality can provide systems of meaning and feelings of strength to cope with stress and adversity. ${ }^{47}$ A recent US national mortality study that found a robust effect of religious attendance after adjusting for a broad range of potential confounding and mediating behavioural, social and psychological variables highlights the need to also explore potential direct effects of religion on health. ${ }^{48}$

\section{Future directions in research}

There are several research needs in the study of spirituality and health. First, there is clearly a need for more careful conceptualisation and measurement of the religiousness/spirituality variable. ${ }^{5,34,49}$ For example, research reveals that $90 \%$ of Americans pray, but there are multiple types of prayer, many different experiences during prayer, and considerable variation within the population in the nature, frequency, content and meaning of prayer. $^{50}$ Understanding the relationship between prayer and health will require consideration of the conditions under which particular dimensions of prayer may be related to specific health outcomes.

A similar case can be made regarding religious attendance. Not all effects of attendance may be inherently spiritual or religious. ${ }^{49}$ Future research needs to distinguish aspects of attendance that may be spiritual from those that may be more social and cultural. Inadequate attention has been given to the meaning of religious attendance and the specific benefits that various respondents may experience as a result of such activity. Congregations also differ in terms of what actually occurs within a religious service. The dimensions of religious participation and the psychosocial aspects of the larger environment can have health consequences. ${ }^{49}$

Research is also necessary to understand the mechanisms by which religion affects health., 54 As noted, even in the most sophisticated research to date, it remains unclear why religious attendance is related to mortality. ${ }^{48}$ More systematic research must examine how a broader range of indicators of health practices, belief systems, role identity, the clergy, social support, and other social and psychological resources may mediate the relationship between religious involvement and health. ${ }^{34,51}$ The extent to which religious and spiritual beliefs can provide a sense of meaning and purpose in life has received inadequate attention.,51 Religious/spiritual beliefs are an important resource that can affect an individual's orientation towards life and the impact of stress on health. Further attention should also be directed towards understanding the biological mechanisms through which religion "gets under the skin". Prior studies have focused on the association between religion and single physiological measures, such as blood pressure or pulse rate. Broader biological measures that incorporate the central nervous system, metabolic parameters and the immune system should be considered. ${ }^{29,51}$

A major research challenge is in defining and measuring spirituality as distinct from religion. ${ }^{32}$ A national survey in the US highlighted the overlap between the two concepts. It found that about half of American adults (52\%) rated themselves as religious and spiritual, $10 \%$ as spiritual only, $9 \%$ as religious only, and $29 \%$ as neither religious nor spiritual. ${ }^{52}$ Self-ratings of spirituality and religiousness predicted a range of social attitudes and religious behaviour. Multidimensional indicators of religion and spirituality with good psychometric properties have now been identified for future research in this area. ${ }^{47,53}$ There are promising initial findings for dimensions of religion and spirituality such as perceived closeness to God; religion or spirituality as a central motivating force in life; meditative practices; and spiritual struggle. ${ }^{47}$

Additional prospective studies are also needed to enhance our understanding of the temporal ordering of the relationship between exposure to spirituality and the timing of health consequences, and to strengthen our confidence in causal inferences. ${ }^{5,34}$ Some spiritual activities, such as prayer, meditation or yoga, tend to produce immediate effects on biological parameters such as blood pressure and heart rate. Other religious and spiritual activities, however, may have a longer "incubation" period before demonstrating results. Studies with short follow-up periods, in addition to retrospective or cross-sectional studies, may overlook important findings.

To date, the vast majority of research on spirituality and health has focused on US populations with strong Judaeo-Christian religious affiliations. Despite the challenges of cross-cultural comparisons, research on diversity in religious orientation and geography is necessary to determine the generalisability of current findings on the association between religion and health. ${ }^{5,29,34,51}$ Even within the US population, earlier research has neglected specific subpopulations, such as Hispanics, Asian Americans, Native Americans and groups of low socioeconomic status. ${ }^{54}$ Some limited evidence indicates that religious attendance is not associated with mortality among highly educated people, suggesting that population-level analyses may mask significant heterogeneity within the population. ${ }^{54}$

\section{Conclusion}

In contrast to prior claims, ${ }^{2}$ levels of spirituality and religion are relatively high in Australia, and findings on the relationship between religion and health in Australia are similar to those in the US. The potential for both positive and negative effects of spirituality on health, combined with the high levels of engagement with spirituality by the Australian population, suggests that this area is ripe for future sustained research. Moreover, Australian patients want their clinicians to incorporate spirituality into their treatment. ${ }^{4,55}$ Australian researchers and clinicians could profitably pay more attention to spirituality - a neglected but important aspect of life that may have significant health consequences.

\section{Competing interests}

None identified.

\section{Author details}

David R Williams, PhD, MPH, Professor ${ }^{1}$

Michelle J Sternthal, MA, Graduate Student ${ }^{2}$

1 Department of Society, Human Development and Health, Harvard University, Boston, Mass, USA.

2 Department of Public Policy and Department of Sociology, University of Michigan, Ann Arbor, Mich, USA.

Correspondence: dwilliam@hsph.harvard.edu

\section{References}

1 Koenig HG, McCullough ME, Larson DB. Handbook of religion and health. New York: Oxford University Press, 2001.

2 Peach HG. Religion, spirituality and health: how should Australia's medical professionals respond? Med J Aust 2003; 178: 86-88.

3 Koenig HG. Religion, spirituality and health: an American physician's response. Med J Aust 2003; 178: 51-52. 


\section{SPIRITUALITY AND HEALTH}

4 D'Souza R, George K. Spirituality, religion and psychiatry: its application to clinical practice. Australas Psychiatry 2006; 14: 408-412.

5 Miller WR, Thoresen CE. Spirituality, religion, and health. An emerging research field. Am Psychol 2003; 58: 24-35.

$6 \mathrm{McNicol}$ T. Where religion and medicine meet: the new faith in medicine. USA Weekend 1996; 7 April: 4-5.

7 Australia Bureau of Statistics. Census of population and housing. Year Book Australia, 2004. Canberra: ABS, 2004. (ABS Cat. No. 1301.0.)

8 Peach HG. Variation in religious affiliations between different populations: metropolitan, rural, agricultural and elderly. Aust J Rural Health 2003; 11: 18-21.

9 Australia Bureau of Statistics. General social survey: summary results, Australia, 2002. Canberra: ABS, 2003. (ABS Cat. No. 4159.0.)

10 Hughes P. Spirituality. http://www.cra.org.au/pages/00000072.cgi (accessed Apr 2007).

11 Moreira-Almeida A, Neto FL, Koenig HG. Religiousness and mental health: a review. Rev Bras Psiquiatr 2006; 28: 242-250.

12 Shreve-Neiger AK, Edelstein BA. Religion and anxiety: a critical review of the literature. Clin Psychol Rev 2004; 24: 379-397.

13 Smith TB, McCullough ME, Poll J. Religiousness and depression: evidence for a main effect and the moderating influence of stressful life events. Psychol Bull 2003; 129: 614-636.

14 Mohr S, Huguelet P. The relationship between schizophrenia and religion and its implications for care. Swiss Med Wkly 2004; 134: 369-376.

15 Razali SM, Hasanah Cl, Aminah K, et al. Religious-sociocultural psychotherapy in patients with anxiety and depression. Aust N Z J Psychiatry 1998; 32: 867-872.

16 Thearle MJ, Vance JC, Najman JM, et al. Church attendance, religious affiliation and parental responses to sudden infant death, neonatal death and stillbirth. Omega (Westport) 1995; 31: 51-58.

17 D'Souza R, Rodrigo A. Spiritually augmented cognitive behavioural therapy. Australas Psychiatry 2004; 12: 148-152.

18 Cotton S, Zebracki K, Rosenthal SL, et al. Religion/spirituality and adolescent health outcomes: a review. J Adolesc Health 2006; 38: 472480.

19 Rew L, Wong YJ. A systematic review of associations among religiosity/ spirituality and adolescent health attitudes and behaviors. J Adolesc Health 2006; 38: 433-442.

20 Abbott-Chapman J, Denholm C. Adolescents' risk activities, risk hierarchies and the influence of religiosity. J Youth Stud 2001; 4: 279-297.

21 Beyers JM, Toumbourou JW, Catalano RF, et al. A cross-national comparison of risk and protective factors for adolescent substance use: the United States and Australia. J Adolesc Health 2004; 35: 3-16.

22 Ano GG, Vasconcelles EB. Religious coping and psychological adjustment to stress: a meta-analysis. J Clin Psychol 2005; 61: 461-480.

23 Pargament KI, McCarthy S, Shah P, et al. Religion and HIV: a review of the literature and clinical implications. South Med J 2004; 97: 1201-1209.

24 Aukst-Margetic B, Margetic B. Religiosity and health outcomes: review of literature. Coll Antropol 2005; 29: 365-371.

25 Stefanek M, McDonald PG, Hess SA. Religion, spirituality and cancer: current status and methodological challenges. Psychooncology 2005; 14: 450-463.

26 Thune-Boyle IC, Stygall JA, Keshtgar MR, et al. Do religious/spiritual coping strategies affect illness adjustment in patients with cancer? A systematic review of the literature. Soc Sci Med 2006; 63: 151-164.

27 Townsend M, Kladder V, Ayele H, et al. Systematic review of clinical trials examining the effects of religion on health. South Med J 2002; 95: 14291434.

28 Benson H, Dusek JA, Sherwood JB, et al. Study of the Therapeutic Effects of Intercessory Prayer (STEP) in cardiac bypass patients: a multicenter randomized trial of uncertainty and certainty of receiving intercessory prayer. Am Heart J 2006; 151: 934-942.

29 Seeman TE, Dubin LF, Seeman M. Religiosity/spirituality and health. A critical review of the evidence for biological pathways. Am Psychol 2003; 58: 53-63.
30 Hummer RA, Rogers RG, Nam CB, et al. Religious involvement and US adult mortality. Demography 1999; 36: 273-285.

31 McCullough ME, Hoyt WT, Larson DB, et al. Religious involvement and mortality: a meta-analytic review. Health Psychol 2000; 19: 211-222.

32 Powell LH, Shahabi L, Thoresen CE. Religion and spirituality. Linkages to physical health. Am Psychol 2003; 58: 36-52.

33 Lee BY, Newberg AB. Religion and health: a review and critical analysis. Zygon 2005; 40: 443-468.

34 Chatters LM. Religion and health: public health research and practice. Annu Rev Public Health 2000; 21: 335-367.

35 Trenholm P, Trent J, Compton WC. Negative religious conflict as a predictor of panic disorder. J Clin Psychol 1998; 54: 59-65.

36 Asser SM, Swan R. Child fatalities from religion-motivated medical neglect. Pediatrics 1998; 101: 625-629.

37 Pargament KI, Koenig HG, Tarakeshwar N, et al. Religious struggle as a predictor of mortality among medically ill elderly patients: a 2-year longitudinal study. Arch Intern Med 2001; 161: 1881-1885.

38 Ferraro KF. Firm believers? Religion, body weight, and well-being. Rev Relig Res 1998; 39: 224-244.

$39 \mathrm{Kim} \mathrm{KH}$. Religion, weight perception, and weight control behavior. Eat Behav 2007; 8: 121-131.

40 Armstrong B, van Merwyk AJ, Coates H. Blood pressure in Seventh-day Adventist vegetarians. Am J Epidemiol 1977; 105: 444-449.

41 Rouse IL, Armstrong BK, Beilin LJ. Vegetarian diet, lifestyle and blood pressure in two religious populations. Clin Exp Pharmacol Physiol 1982; 9: 327-330

42 Kune GA, Kune S, Watson LF. Perceived religiousness is protective for colorectal cancer: data from the Melbourne Colorectal Cancer Study. J R Soc Med 1993; 86: 645-647.

43 Fraser GE. Diet as primordial prevention in Seventh-Day Adventists. Prev Med 1999; 29(6): S18-S23.

44 Willett W. Lessons from dietary studies in Adventists and questions for the future. Am J Clin Nutr 2003: 78 (3 Suppl): 539S-543S.

45 Wallace JM Jr, Forman TA. Religion's role in promoting health and reducing risk among American youth. Health Educ Behav 1998; 25: 721 741.

46 Strawbridge WJ, Shema SJ, Cohen RD, et al. Religious attendance increases survival by improving and maintaining good health behaviors, mental health, and social relationships. Ann Behav Med 2001; 23: 68-74.

47 Hill PC, Pargament KI. Advances in the conceptualization and measurement of religion and spirituality. Implications for physical and mental health research. Am Psychol 2003; 58: 64-74.

48 Musick MA, House JS, Williams DR. Attendance at religious services and mortality in a national sample. J Health Soc Behav 2004; 45: 198-213.

49 Williams DR. The measurement of religion in epidemiologic studies: problems and prospects. In: Levin JS, editor. Religion in aging and health: theoretical foundations and methodological frontiers. London: Sage Publications, 1994: 125-148.

50 Poloma MM, Gallup GH. Varieties of prayer: a survey report. Philadelphia: Trinity Press International, 1991.

51 George LK, Ellison CG, Larson DB. Explaining the relationships between religious involvement and health. Psychol Inq 2002; 13: 190-200.

52 Shahabi L, Powell LH, Musick MA, et al. Correlates of self-perceptions of spirituality in American adults. Ann Behav Med 2002; 24: 59-68.

53 Idler EL, Musick MA, Ellison CG, et al. Measuring multiple dimensions of religion and spirituality for health research: conceptual background and findings from the 1998 General Social Survey. Res Aging 2003; 25: $327-$ 365.

54 Hummer RA, Ellison CG, Rogers RG, et al. Religious involvement and adult mortality in the United States: review and perspective. South Med J 2004; 97: 1223-1230.

55 Mohr WK. Spiritual issues in psychiatric care. Perspect Psychiatr Care 2006; 42: 174-183.

(Received 26 Sep 2006, accepted 20 Mar 2007) 